\title{
The concentrations of selected blood serum proteins in calves during the first three months of life
}

\author{
Csilla Tóthová, Oskar Nagy, Veronika Nagyová, Gabriel Kováč \\ University of Veterinary Medicine and Pharmacy, Clinic for Ruminants, \\ Košice, Slovak Republic \\ Received April 20, 2015 \\ Accepted February 10, 2016
}

\begin{abstract}
This study was aimed at the evaluation of changes in the concentrations of selected blood serum proteins in calves during the first three months of life, including precolostral, colostral, milk, transitional and solid feeding period. Nine clinically healthy calves were used in this study. The first blood sampling was performed before the colostrum intake (day 0) and then at 1, 2, 7, $14,30,60$, and 90 days of age. Blood serum was analyzed for the concentrations of $\alpha_{1}$-fetoprotein, prealbumin, transferrin, and lactoferrin. The results showed significant changes in the serum concentrations of all the evaluated proteins in calves during the first three months of life $(P<0.01$ and $P<0.001)$. At birth, the mean concentration of $\alpha_{1}$-fetoprotein was low and increased more than $\times 8$ at one day after colostrum intake, then a gradual decrease was found up to day 30 of life. Similar tendency was observed in the concentrations of prealbumin and lactoferrin. While the concentrations of prealbumin increased approximately $\times 3.5$ at one day after colostrum intake, the serum lactoferrin values showed approximately 1.5 -fold increase. A subsequent gradual decrease from the $2^{\text {nd }}$ day of life was found for both prealbumin and lactoferrin. In the concentrations of transferrin, a significant increase was observed on day $7(P<0.05)$. The highest values were found at the age of 14 and 30 days. These results suggest that concentrations of these proteins in calves are markedly altered during the postnatal period, which should be taken into consideration for their precise interpretation in young animals.
\end{abstract}

Cattle, postnatal period, $\alpha_{1}$-fetoprotein, prealbumin, transferrin, lactoferrin

It was estimated that up to 10,000 proteins may be commonly present in blood serum. The major protein constituents include albumin, immunoglobulins, haptoglobin, transferrin and lipoproteins (Burtis and Ashwood 2001). In addition, blood serum also contains many other proteins that are secreted by cells and tissues at very low concentrations and/or in veterinary clinical biochemistry are relatively underutilised (Wrotnowski 1998). These

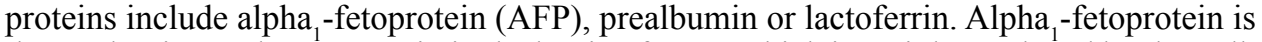
the predominant plasma protein in the bovine foetus, which is mainly produced by the yolk sac and at the later period by the foetal liver (Bader et al. 2004). Because of its biochemical similarity to albumin, AFP could be a carrier protein, or even take part in the metabolism of bilirubin (Thomas and Schreiber 1985; Polberger et al. 1990). Prealbumin, also known as transthyretin, is a negative acute phase reactant, serum concentrations of which fall due to decreased synthesis in inflammation and stress, as well as in conditions associated with protein malnutrition (Beck and Rosenthal 2002). Transferrin like lactoferrin is an iron binding glycoprotein, which inhibits the multiplication and growth of certain viral, bacterial, and fungal organisms by iron inhibition (Kaplan et al. 1991). Moreover, lactoferrin stimulates both local and systemic immune response, and due to the increase in its concentrations during most inflammatory reactions, several authors classified lactoferrin as an acute phase protein (Kanyshkova et al. 2001). Some of these proteins may serve as important disease markers having essential role in the initial diagnostic evaluation and follow-up during therapy. They have the potential to inform regarding the

Address for correspondence:

MVDr. Csilla Tóthová, PhD.

Clinic for Ruminants

University of Veterinary Medicine and Pharmacy

Komenského 73, 04181 Košice, Slovak Republic

Phone: +421915493082

Fax: +421556711674

E-mail: tothova@uvm.sk

http://actavet.vfu.cz/ 
risk of disease or to allow early detection for more effective treatment (Hanash 2011). On the other hand, physiologically elevated protein concentrations in young animals must also be considered in the diagnosis. However, in the availalable literature there is a lack of information concerning changes in the concentrations of some proteins in calves during the early postnatal period.

Several studies indicated that the most intense adaptive changes to the extra-uterine life and new environment in calves occur during the early postnatal period (Herosimczyk et al. 2013). In this critical period, intense structural and functional changes in many vital organs take place, including the morphological growth and functional maturation of the gastrointestinal tract (Skrzypczak et al. 2011; Herosimczyk et al. 2012). Colostrum is the first source of nutrition in neonatal ruminants, supplying not only nutritional substances essential for proper growth and development of the organism, but having also a fundamental biological function, promoting immunoglobulin transfer from the dam to the newborn prior to the cessation of macromolecular transport (Nowak and Poindron 2006). It also abounds in a wide variety of bioactive components responsible for initiating, controlling and supporting many biological processes, including the develeopment of immunity in the newborn (Uruakpa et al. 2002). Moreover, the intake of colostrum initiates a number of physiological processes, resulting in different metabolic changes, e.g. increased synthesis of endogenous proteins and qualitative and quantitative changes in the plasma protein composition (Herosimczyk et al. 2013). In the later postnatal period, further structural, functional and metabolic alterations take place in calves, connected to the adaptation to new environmental factors, foreign antigens, changes in nutrition and type of nutrient supplementation. The studies focused on the analysis of the concentrations of some specific blood proteins during the growth and development of calves are rather sparse. Therefore, the objective of this study was to evaluate the changes in the concentrations of selected serum proteins ( $\alpha_{1}$-fetoprotein, prealbumin, transferrin and lactoferrin) in clinically healthy calves during the first three months of life, and to study these changes with regard to the process of adaptation to postnatal life and changes in nutrition, including precolostral, colostral, milk, transitional, and solid feeding period.

\section{Materials and Methods}

Nine clinically healthy calves ( 6 males and 3 females) of the black pied Holstein-Friesian breed and its crossbreeds were included into this study. The calves were born at the Clinic for Ruminants of the University of Veterinary Medicine and Pharmacy in Kosice with a mean birth weight of $36.1 \pm 2.3 \mathrm{~kg}$ and a mean body weight of $143.8 \pm 5.5 \mathrm{~kg}$ at the end of the $3^{\text {rd }}$ month. Calves were born as singles from 4 cows and 5 heifers with pregnancies of normal lenght and uncomplicated births. After birth they were not separated from their dams and were kept individually in pens. The animals were stabled on straw litter. Calves were allowed to suck their dams voluntarily and they received the first colostrum within $2 \mathrm{~h}$ after birth. Subsequently the calves received colostrum and whole milk according to their appetite without restriction of the sucking frequency and volume during the day. The transition to a solid diet lasted until the age of 2.5 months. During this period, the calves were fed gradually decreasing amounts of milk, and increasing amounts of concentrates. The calves had free access to water and hay during the time under study. The health status of the calves was evaluated daily. Clinical examination included behaviour, appetite, rectal temperature, heart and respiratory rates, pulmonary sounds, nasal discharge, eye discharge, navel infection and faecal consistency. All the animals were clinically healthy and in good general health condition without any obvious clinical signs of diseases during the time of the study.

The first blood sampling was performed in the calves before the colostrum intake (precolostral sample, $\mathrm{d}$ 0) within 30 min after birth and then at 1, 2, 7, 14, 30, 60, and 90 days of age. Blood was collected by direct puncture of v. jugularis into serum gel separator tubes without anticoagulant (Meus, Piove di Sacco, Italy). Blood samples were allowed to clot at room temperature, and then centrifuged at $3,000 \times g$ for $30 \mathrm{~min}$ to separate serum. The harvested blood serum was dispensed into plastic tubes, and stored at $-20{ }^{\circ} \mathrm{C}$ until analysed.

Blood serum was analysed for the concentrations of $\alpha_{1}$-fetoprotein (AFP, $\left.\mu \mathrm{g} / \mathrm{l}\right)$, prealbumin (PALB, mg/l), transferrin (Trf, g/l) and lactoferrin (Lf, mg/l). Alpha -fetoprotein was analysed by sandwich enzyme linked immunosorbent assay (ELISA) using commercial kits (Cloud-Clone Corp., Houston, USA). Prealbumin was assessed using commercial solid-phase ELISA kits (BlueGene Biotech, Shanghai, China) appliyng the competitive enzyme immunoassay technique. The concentrations of transferrin were determined by commercial 
immunoperoxidase assay kits (Icl Immunology Consultants Laboratory, Inc., Portland, USA). Lactoferrin was measured by competitive ELISA technique using commercially available tests (Bio-X Diagnostics, Jemelle, Belgium). The reading of absorbancies and the consecutive calculation of final concentrations of these proteins were performed on automatic microplate reader Epoch (BioTek, Winooski, USA).

Arithmetic means (x) and standard deviations (SD) for each evaluated protein and sample collection time were calculated using descriptive statistical procedures. The significance of the effect of age on the concentrations of the analyzed variables during the whole monitored period was examined by non-parametric Friedman's rank sum test $(P$-value). The significances of the differences in the results between the sample collection points were evaluated by Dunn's multiple comparisons test. All statistical analyses were carried out using the programme GraphPad Prism V5.02 (GraphPad Software Inc., California, USA).

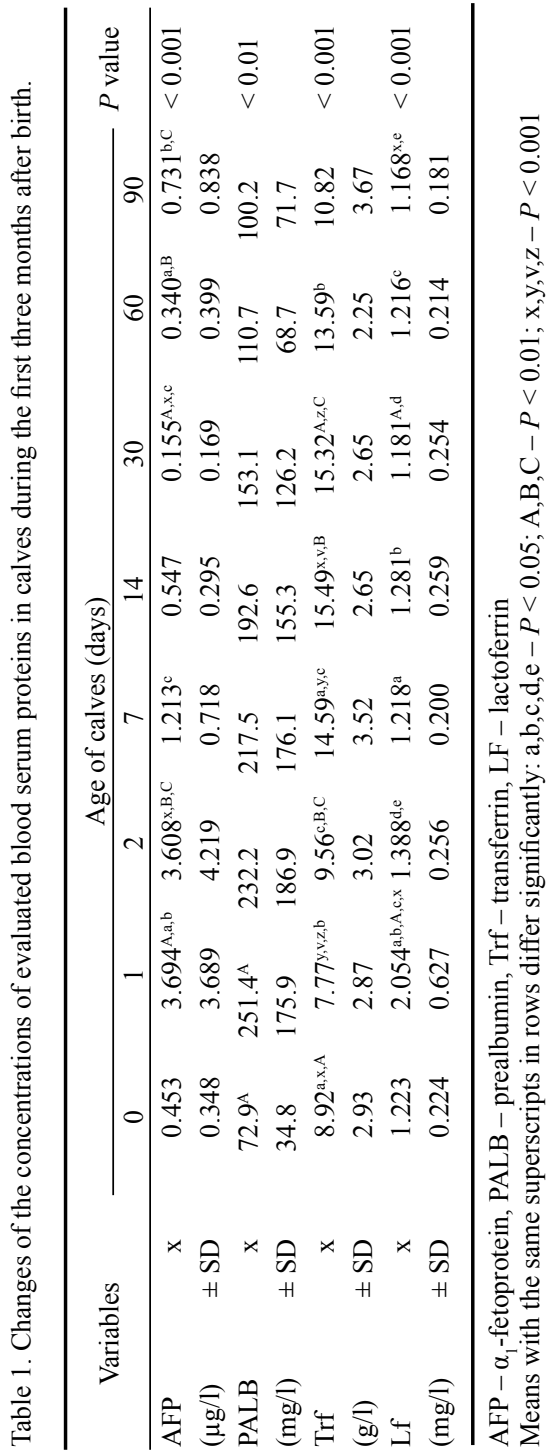

\section{Results}

The concentrations of AFP, prealbumin, transferrin and lactoferrin during the first three months of life showed significant changes in the calves (Table $1, P<0.01$ and $P<0.001$ ). At birth, the mean concentration of AFP was only $0.453 \mu \mathrm{g} / \mathrm{l}$, and the values increased markedly $($ more than $\times 8$ ) one day after colostrum intake. Since the $2^{\text {nd }}$ day after birth a gradual significant decrease was found up to day 30 of life $(P<0.01)$, with following repeated increase of values till the end of the evaluated period (Fig. 1a). Similar changes were observed in the concentrations of prealbumin. Its lowest mean concentration was recorded at birth, which increased significantly one day after colostrum intake $(P<0.01)$. From the $2^{\text {nd }}$ day till the end of the $3^{\text {rd }}$ month of life a gradual decrease of values was observed (Fig. $1 b$ ). Significant changes in relation to the age of calves were observed also in the concentrations of transferrin $(P<0.001)$. The values recorded shortly after birth (d 0) and on day 1 and 2 of life were roughly uniform (Fig. 1c). A significant increase of the concentrations of transferrin was recorded on day 7 with a further slight increase of values being the highest at the age of 14 days. From day 30 of life, a gradual decrease of concentrations was observed till the end of the evaluated period. Sampling time had a significant effect also on the concentrations of lactoferrin $(P<0.001)$. Its concentrations increased markedly 1 day after colostrum intake (more than $\times 1.5$ ), with a subsequent gradual decrease up to day 7 of life (Fig. 1d). The concentrations recorded in the next period till the end of the first three months of life were rougly uniform and comparable with the mean value found shortly after birth (day 0 ).

\section{Discussion}

The establishment of reliable physiological values in young animals is especially important 
a

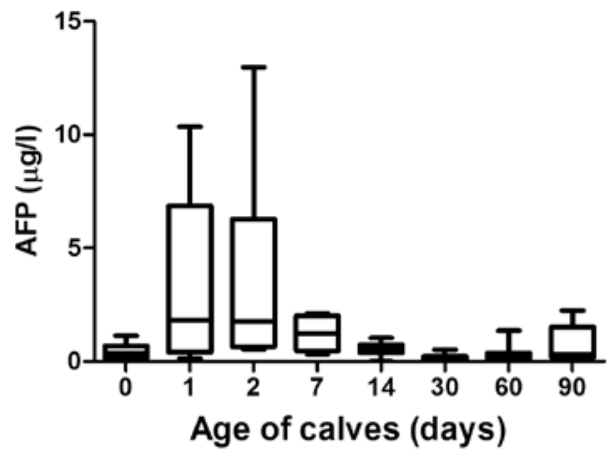

C

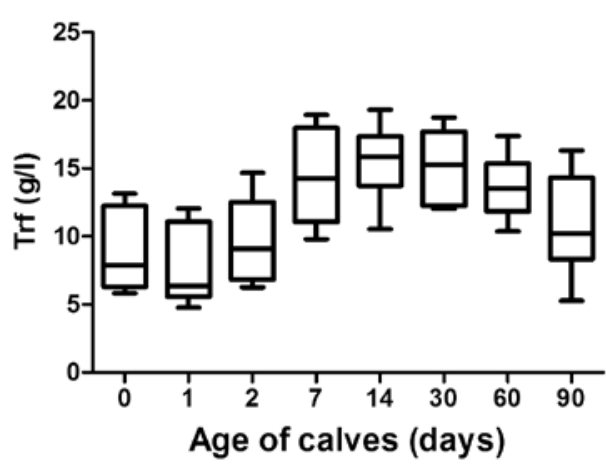

b

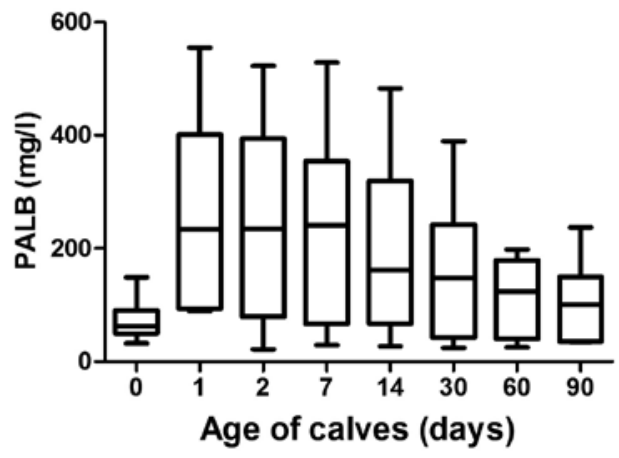

d

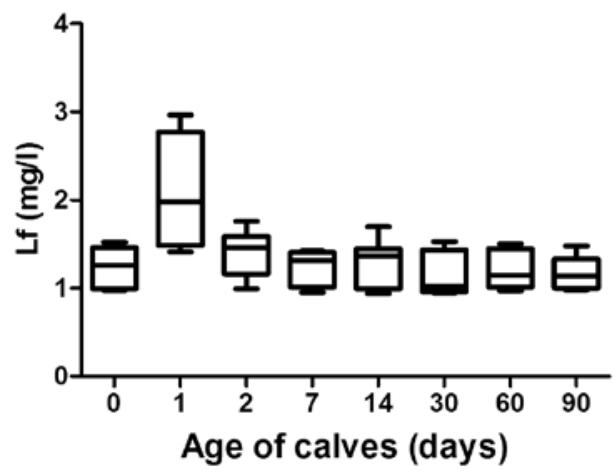

Figure 1a-d. Distribution of the concentrations of $\alpha_{1}$-fetoprotein (a), prealbumin (b), transferrin (c), and lactoferrin (d) in calves during the first three months of life. The plots show the median (line within box), $25^{\text {th }}$ and $75^{\text {th }}$ percentiles (box), minimal and maximal values (whiskers).

in the diagnosis and follow-up of some diseases. However, the physiological values of some special proteins, including $\alpha_{1}$-fetoprotein, prealbumin, transferrin and lactoferrin in newborn and young calves are not completely described and the data available are rather contradictory. The results of this study showed a significant effect of age on the concentrations of the evaluated proteins during the early and later postnatal life in calves. Highly significant changes were observed in the concentrations of AFP, with relatively low values at birth and marked increase 1 day after colostrum intake. Smith et al. (1979) have demonstrated that the concentrations of AFP in foetal bovine plasma reaches the highest values in the $3-4^{\text {th }}$ month of foetal period, which is followed by a significant decrease until birth. In our study, the mean concentration of AFP observed in calves at birth was only $0.453 \mu \mathrm{g} / \mathrm{ml}$. Considerably higher values were reported by Yamada et al. (1995) in newborn puppies at birth $(14.08 \mathrm{mg} / \mathrm{ml})$, which had fallen to $0.766 \mathrm{mg} / \mathrm{ml}$ at 1 week of age. A possible explanation for this difference is that the placentae in cows have more layers of tissue separating foetal and maternal blood than the placentae in other species (Smith et al. 1979). Blohm et al. (1998) evaluated the concentration of AFP in babies, which was $41.687 \mathrm{ng} / \mathrm{ml}$ at birth and decreased by $50 \%$ in the first 4 weeks of life. Bader et al. (2004) documented a decline in AFP concentrations in the first hours of life which may represent 
the physiological effect on the foetal tissues changing from an intrauterine to an extrauterine environment with a decrease in the production of foetal proteins in the liver. According to Lee et al. (1989), following the initial decline in the concentrations of AFP within hours after birth, the AFP values tend to stabilize during the rest of the first week, before the rapid decline that follows. On the other hand, our results showed a marked increase of AFP concentrations 1 day after colostrum intake, with following gradual decrease of values up to day 30 of life. The observation of relatively higher values of AFP after birth may be explained by its synthesis (not ceasing entirely at birth) by foetal hepatocytes that sustain transient production of AFP during the early postnatal period (Çorapçioĝlu et al. 2004). Moreover, colostrum contains many non-nutrient substances and immune factors, including alpha $\mathrm{A}_{1}$-fetoprotein, which may be responsible for the increased concentrations of AFP in calves one day after colostrum intake (Gopal and Gill 2000). On the other hand, AFP is an important disease marker and is often used to detect and diagnose tumours of the liver, testes, and ovaries (Thomas and Schreiber 1985), but the calves used in this study were clinically healthy and the increase of AFP concentrations should not be related to these pathological conditions.

Significant age related variations were seen for the concentrations of prealbumin with a marked increase of values one day after colostrum intake and a consecutive gradual decrease till the end of the $3^{\text {rd }}$ month of life. The serum concentrations of prealbumin at birth and their changes during the early postnatal period of calves are less well documented. Thomas and Schreiber (1985) found in neonatal rats low concentrations of prealbumin in the immediate postnatal period, which increased at the time when the concentrations of both thyroxine and corticosterone increased. A progressive increase of prealbumin concentrations with postnatal age was reported by Kanakoudi et al. (1995) in human infants. Similarly, Cardoso and Falção (2007) also observed a significant increase of prealbumin concentrations from birth to day 28 in preterm infants with very low birth weight. According to these authors, the serum short-term proteins such as prealbumin, retinol-binding protein and transferrin can reflect the recent protein status and balance between synthesis and degradation. Prealbumin has been shown also by MacDonald et al. (2005) to reflect recent protein intake and to predict future weight gain. The aforementioned authors concluded that if the serum concentrations of prealbumin remain stable or even increase, it can be presumed that the newborn is in reasonable nitrogen balance and will gain weight subsequently. Moreover, as described by Rona (1998) and Yamada et al. (2002), laboratory analyses of the immune factors from bovine colostrum show that it contains among others a small amount of prealbumin, transferrin, as well as lactoferrin, having a special physiological relevance to the health and development of calves. Thus, the increase of serum prealbumin concentrations in calves observed in our study after colostrum intake may reflect adequate nutrition, as well as its hepatic synthesis due to adequate protein and energy intake (Ingenbleek and Young 1994). Regarding the concentrations of transferrin, our results showed its marked increase from day 7 of life. Ilić et al. (2006) found in neonatal piglets that from nearly undetectable values at birth, the concentrations of transferrin increased continuously from the second day of life, suggesting its abundant absorption from colostrum or its intensive synthesis taking place on the first days after birth. Similarly, Martin et al. (2005) presented low concentrations of transferrin in newborn piglets before suckling. Changes in the serum transferrin concentrations in relation to the age were studied by Plomteux et al. (1987) in human infants with the lowest values found in neonates. According to Kratz et al. (2002), serum concentrations of transferrin during the neonatal period are maintained at a fairly constant level of about $50 \%$ of the adult values, and if the neonatal concentrations fall during the postnatal period, it means that the rate of protein synthesis is probably lower than the rate of degradation. Thus, the increase of transferrin concentrations observed in our study from day 7 of life 
may reflect a good nutritional status of the calves. On the other hand, concentrations of transferrin in blood serum may be related to iron metabolism as suggested by Moser et al. (1994), who found values exceeding $8 \mathrm{~g} / \mathrm{l}$ in veal calves with iron deficiency. However, seeing that there are scarce reports describing serum concentrations of prealbumin and transferrin in calves at birth and in the early postnatal period, further studies are needed.

The mean serum concentration of lactoferrin observed in our study in calves at birth was $1.22 \mathrm{mg} / \mathrm{ml}$, which increased more than $\times 1.5$ at one day after colostrum intake and then decreased gradually up to day 7 of life. Similarly, Hurley and Sixiang (2000) presented in newborn calves low serum concentration of lactoferrin $(1.09 \mu \mathrm{g} / \mathrm{ml})$ immediately after birth, which increased approximately $\times 10$ at $8 \mathrm{~h}$ after the first colostrum intake and subsequently gradually decreased until the second day of life. These authors suggested that the increase of serum lactoferrin concentrations was probably caused by its absorption from the colostrum, which contains high amounts of lactoferrin, varying between 1 and $5 \mathrm{mg} / \mathrm{ml}$ (Stelwagen et al. 2009). Talukder et al. (2002) also found a relatively low concentration of lactoferrin in blood plasma of calves at birth $(0.20 \mu \mathrm{g} /$ $\mathrm{ml}$ ), which increased approximately $\times 10$ at $6 \mathrm{~h}$ after the first colostrum intake, but these higher concentrations sustained only for the first $12 \mathrm{~h}$ of life. The increasing tendency of serum lactoferrin concentration observed in our study one day after colostrum intake was lower (1.5-fold) compared to the results of the aforementioned authors, which might be affected by the biological activity of absorbed colostral lactoferrin, which is rapidly cleared from the blood of calves (about $12 \mathrm{~h}$ after colostrum intake) (Hurley and Sixiang 2000). Moreover, concentrations of lactoferrin found in the blood of newborns are dependent on the concentration of lactoferrin in the colostrum fed, the amount of colostrum fed, and the time after the feeding of colostrum (Cheng et al. 2008). The potential usefulness of lactoferrin as a predictor of passive imunity was evaluated by Gokce et al. (2014) in lambs. They found only a weak linear relationship between serum lactoferrin and immunoglobulin G concentrations in 1-, 2-, 4- and 7-day-old healthy lambs, while healthy lambs had significantly higher lactoferrin concentrations than ill lambs in the neonatal period. However, whether high serum concentrations of lactoferrin in newborn calves may affect the developing immune system, was not demonstrated.

In conclusion, our results showed significant changes in the concentrations of evaluated serum proteins in calves during the first three months of life. These changes reflect the response of calves to colostrum intake and changes in nutrition during the growth and development of calves facilitating normal adaptation to extrauterine life. Thus, the changes in their concentrations described in the study during the postnatal period are not necessarily caused by some diseaserelated factors, but may reflect the nutritional status and physiological adaptation of newborns to extrauterine life. These changes in young animals should be taken into consideration when analysing and interpreting the concentrations of $\alpha_{1}$-fetoprotein, prealbumin, transferrin, as well as lactoferrin. Presented results contribute to the knowledge about the changes of the serum proteins in newborn and young calves and are of great importance, because there are only few reports describing their concentrations at birth and in the early postnatal period. Seeing that some of the evaluated proteins may be useful nutritional and disease markers also in cattle, there is a need for the establishment of age-specific reference values for these variables when considering precise interpretation of laboratory results.

\section{Acknowledgements}

This work was supported by the Scientific Grant Agency of the Ministry of Education of the Slovak Republic, Nos $1 / 0447 / 14$ and $1 / 0154 / 15$.

\section{References}

Bader D, Riskin A, Vafsi O, Tamir A, Peskin B, Israel N, Merksamer R, Dar H, David M 2004: Alpha-fetoprotein in the early neonatal period - a large study and review of the literature. Clin Chim Acta 349: 15-23 
Beck FK, Rosenthal TC 2002: Prealbumin: a marker for nutritional evaluation. Am Fam Physician 65: $1575-1578$

Blohm ME, Vesterling-Hörner D, Calaminus G, Göbel U 1998: Alpha 1-fetoprotein (AFP) reference values in infants up to 2 years of age. Pediatr Hematol Oncol 15: 135-142

Burtis CA, Ashwood ER 2001: Tietz Fundamentals of Clinical Chemistry. $5^{\text {th }}$ ed., W. B. Saunders Company, Philadelphia, $1091 \mathrm{p}$.

Cardoso LEMB, Falção MC 2007: Nutritional assessment of very low birth weight infants: relationships between anthropometric and biochemical parameters. Nutr Hosp 22: 322-329

Cheng JB, Wang JQ, Bu DP, Liu GL, Zhang CG, Wei HY, Zhou LY, Wang JZ 2008: Factors affecting the lactoferrin concentration in bovine milk. J Dairy Sci 91: 970-976

Çorapçioĝlu F, Türker G, Aydoĝan A, Sarper N, Duman C, Arisoy AE 2004: Serum alpha fetoprotein levels in healthy full-term neonates and infants. Marmara Medical J 17: 1-7

Gokce E, Atakisi O, Kirmizigul AH, Unver A, Erdogan HM 2014: Passive imunity in lambs: Serum lactoferrin concentrations as a predictor of IgG concentration and its relation to health status from birth to 12 weeks of life. Small Ruminant Res 116: 219-228

Gopal PK, Gill HS 2000: Oligosaccharides and glycoconjugates in bovine milk and colostrum. British J Nutr 84: S69-S74

Hanash SM 2011: Why have protein biomarkers not reached the clinic? Genome Med 3: 66

Herosimczyk A, Lepczyński A, Ożgo M, Skrzypczak WF 2012: Effect of age and food intake on the selected blood plasma/serum proteins in calves during the early postnatal period. Med Weter 68: 265-268

Herosimczyk A, Lepczyński A, Ożgo M, Dratwa-Chalupnik A, Michalek K, Skrzypczak WF 2013: Blood plasma protein and lipid profile changes in calves during the first week of life. Polish J Vet Sci 16: 425-434

Hurley W, Sixiang Z 2000: Absorption of colostral lactoferrin in newborn calves. Illini DairyNet Papers 11/15

Ilić V, Petakov M, Stojanović N, Jovčić G, Bugarski D, Grbović T, Božić T, Kovačević-Filipović M 2006: Relationship between total iron binding capacity and transferrin concentration in neonatal piglets treated with iron-dextran. Acta Vet Beograd 56: 235-242

Ingenbleek Y, Young V 1994: Transthyretin (prealbumin) in health and disease: nutritional implications. Annu Rev Nutr 14: 495-533

Kanakoudi F, Drossou V, Tzimouli V, Diamanti E, Konstantinidis T, Germenis A, Kremenopoulos G 1995: Serum concentrations of 10 acute-phase proteins in healthy term and preterm infants from birth to age 6 months. Clin Chem 41: 605-608

Kanyshkova TG, Buneva VN, Nevisnky GA 2001: Lactoferrin and its biological functions. Biochem 66: 1-7

Kaplan J, Jordan I, Sturrock A 1991: Regulation of the transferrin - independent iron transport system in cultured cells. J Biol Chem 266: 2997-3004

Kratz A, Lee-Lewandrowski E, Lewandrowski KB 2002: The plasma proteins. In: McClatchey KD (Ed.): Clinical Laboratory Medicine. $2^{\text {nd }}$ ed., Lippincott Williams \& Wilkins, Philadelphia, USA, pp. 263-281

Lee PI, Chang MH, Chen DS, Lee CY 1989: Serum alpha-fetoprotein levels in normal infants: a reappraisal of regression analysis and sex difference. J Pediatr Gastroenterol Nutr 8: 19-25

MacDonald MG, Mullett MD, Seshia MMK 2005: Avery's Neonatology: Pathophysiology \& Management of the Newborn. 6th ed., Lippincott Williams \& Wilkins, Philadelphia, USA, pp. 380-413

Martin M, Tesouro MA, Gonz Am N, Pi A, Lampreave F 2005: Major plasma proteins in pig serum during postnatal development. Reprod Fertil Dev 17: 439-445

Moser M, Pfister H, Bruckmaier RM, Rehage J, Blum JW 1994: Blood serum transferrin concentration in cattle in various physiological states, in veal calves fed different amounts of iron, and in cattle affected by infectious and non-infectious diseases. Zentralbl Veterinarmed A 41: 413-420

Nowak R, Poindron P, 2006: From birth to colostrum: early steps leading to lamb survival. Reprod Nutr Dev 46: 431-446

Plomteux G, Charlier C, Albert A, Farnier M, Pressac M, Vernet M, Paris M, Dellamonica C, Dezier JF 1987: Reference values of serum transferrin in newborn infants, children and adults. Ann Biol Clin 45: 622-629

Polberger SK, Fex G, Raiha NC 1990: Concentration of twelve plasma proteins at birth in very low birthweight and in term infants. Acta Paediatr Scand 79: 729-736

Rona ZP 1998: Bovine colostrum emerges as immune system modulator. Am J Natural Med 3: 19-23

Skrzypczak WF, Ozgo M, Lepczynski A, Herosimczyk A 2011: Defining the blood plasma protein repertoire on seven day old dairy calves - a preliminary study. J Physiol Pharmacol 62: 313-319

Smith KM, Lai PCW, Robertson HA, Church RB, Lorscheider FL 1979: Distribution of alpha,-fetoprotein in fetal plasma, allantoic fluid, amniotic fluid and maternal plasma of cows. J Reprod Fert 57: 235-238

Stelwagen K, Carpenter E, Haigh B, Hodgkinson A, Wheeler TT 2009: Immune components of bovine colostrum and milk. J Anim Sci 87: 3-9

Talukder MJR, Takeuchi T, Harada E 2002: Transport of colostral macromolecules into the cerebrospinal fluid via plasma in newborn calves. J Dairy Sci 85: 514-524

Thomas T, Schreiber G 1985: Acute-phase response of plasma protein synthesis during experimental inflammation in neonatal rats. Inflammation 9: 1-7

Uruakpa FO, Ismond MAH, Akobundu ENT 2002: Colostrum and its benefits: a review. Nutr Res 22: $755-767$ 
Yamada T, Kakinoki M, Totsuka K, Ashida Y, Nishizono K, Tsuchiya R, Kobayashi K 1995: Purification of canine alpha-fetoprotein and alpha-fetoprotein values in dogs. Vet Immunol Immunopathol 47: 25-33

Yamada M, Murakami K, Wallingford JC, Yuki Y 2002: Identification of low-abundance proteins of bovine colostral and mature milk using two-dimensional electrophoresis followed by microsequencing and mass spectrometry. Electrophoresis 23: 1153-1160

Wrotnowski C 1998: The future of plasma proteins. Genet Eng News 18: 14 